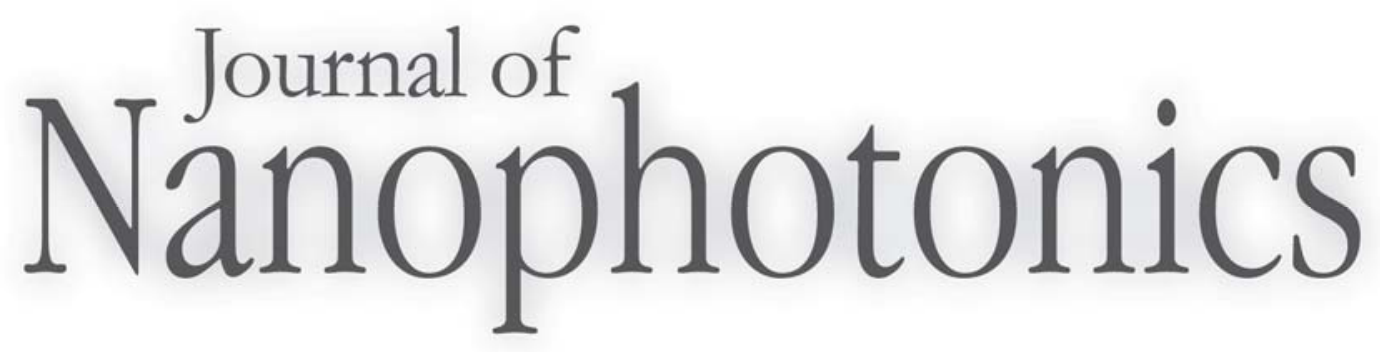

SPIEDigitalLibrary.org/jnp

\title{
Editorial: Very unique omelet concocted by a head chef is a revolutionary breakthrough
}

Akhlesh Lakhtakia 


\title{
Editorial: \\ Very unique omelet concocted by a head chef is a revolutionary breakthrough
}

\author{
Akhlesh Lakhtakia \\ Editor-in-Chief
}

Hyperbole is used to strongly impress the reader (or the listener). Occasional use of hyperbole can be delightful, but frequent occurrence engenders indifference at best and irritation at worst.

Researchers are increasingly tempted to employ hyperbole in describing their work. We all know of some researchers who view their own work as of stratospheric elevation: every paper of theirs reports a breakthrough, whereas the papers of others are not worthy of their attention. But, thanks to aggressive science journalism, breakthroughs have become so common that busy readers can be expected to notice only key breakthroughs [1] and revolutionary breakthroughs [2] these days. The situation is probably not unlike how some chefs — each the head of a professional kitchen—-became head chefs a few decades ago!

Traditionally, researchers are expected to be modest when formally presenting their own work. Though its authors' enthusiasm should be transmitted through a paper, and even some speculation as to the implications of the conclusions following from the obtained results should be included [3], adjectives to intensify the importance of the reported research must be used with caution. Superlatives should not be used at all, high praise for one's own work being best left for others to heap upon it. But even when extolling the works of other researchers, intensification must not be nonsensical. As an example, the phrase very unique is vacuous.

Unintended intensification could arise from either a low level of familiarity with the nuances of a language or unbridled enthusiasm for a research area. Unintended intensification could also arise from mimicking the styles of presentation in certain journals with a beauty pageant for every issue.

Intentional intensification is very likely a spillover from a research proposal. With the chance of success for a research proposal nowadays around 5\%, researchers in the US routinely incorporate grandiose claims for the intellectual merit and the benefit to humanity of the proposed research. Often, in order to attract the attention of a reviewer flipping through 20 pages of a densely formatted document, these claims are either italicized or put in boldface or both. Colorful figures with little direct relevance to the proposed research are also inserted in these proposals. And, as US practices often set the tone for the rest of the world, researchers elsewhere are becoming less shy too.

The trend is deplorable, if only because intensification has no bounds. Sooner or later, some head chefs will have to be promoted to principal head chefs and revolutionary breakthroughs will have to be touted as super ultra revolutionary breakthroughs, although mercifully, very unique will not be topped.

Contributors to the Journal of Nanophotonics are enjoined to continue writing modestly.

\section{References}

[1] The front cover of the July-August 2010 of Materials Today is graced by the announcement of "Key breakthroughs in chemical sensors".

[2] http://www.photonicsonline.com/article.mvc/Revolutionary-Breakthrough-InTerahertz-0001 (accessed September 20, 2010).

[3] A. Lakhtakia, "A manual for Journal of Nanophotonics authors," J. Nanophoton. 1, 019902 (2007) [doi: 10.1117/1.2802052]. 